\title{
PELATIHAN BERMAIN PADA IBU MENINGKATKAN KELEKATAN ANAK
}

\author{
Eka Oktavianto', Karimah', Endar Timiyatun'1, Atik Badi'ah ${ }^{2}$ \\ ${ }^{1}$ Program Studi IImu Keperawatan STIKes Surya Global, Yogyakarta \\ ${ }^{2}$ Program Studi Ilmu Keperawatan Poltekkes Kemenkes, Yogyakarta \\ Email : ekaoktavianto12@gmail.com
}

\begin{abstract}
ABSTRAK
Latar Belakang: Masalah kelekatan antara ibu dan anak masih terjadi pada saat ini. Praktik pengasuhan memainkan peranan penting terjadinya masalah kelekatan ini. Kelekatan bukanlah ikatan yang terjadi secara alamiah, ada serangkaian proses yang harus dilalui untuk membentuknya. Permasalahan kelekatan ini perlu untuk diatasi. Salah satu caranya adalah dengan mengadakan pelatihan bermain pada ibu.

Tujuan: Penelitian ini bertujuan untuk mengetahui pengaruh pelatihan bermain pada ibu terhadap kelekatan anak

Metode: Jenis penelitian ini adalah pra-eksperimantal dengan menggunakan desain one-grup pre-test \& post-test. Teknik pengambilan sampel menggunakan purposive sampling dengan jumlah sampel 18 responden. Uji statistik menggunakan wilcoxon test. Instrumen yang digunakan adalah Attachment Q-Set (AQS).

Hasil: Terdapat peningkatan skor kelekatan sebelum dan sesudah pelatihan bermain pada ibu. Skor rata-rata sebelum pelatihan bermain sebesar 111.83, sesudah pelatihan bermain (post-test 1) sebesar 137.44 (mean difference $=25.61$ ) dan pada post-test 2 sebesar 140.05 (mean difference $=28.22$ ). Hasil uji wilcoxon didapatkan nilai $p=0.000$ (nilai $p<0.050$ ).

Kesimpulan: Ada pengaruh pelatihan bermain pada ibu terhadap kelekatan anak.
\end{abstract}

Kata Kunci: Pelatihan Bermain, Ibu, Kelekatan Anak

\section{PENDAHULUAN}

Anak usia prasekolah di Indonesia jumlahnya cukup besar. Data dari kementerian pendidikan dan kebudayaan (2013), jumlah anak umur 0-6 tahun di Indonesia sebesar 18.520 .685 jiwa (Kemendikbud, 2013). Data dari Profil Kesehatan D.I.Y pada tahun 2013, jumlah anak usia 0-4 tahun sebanyak 263.785 jiwa dan usia 4-9 tahun sebanyak 261.196 jiwa dari jumlah penduduk D.I. Yogyakarta sebanyak 3.630.720 jiwa (Dinkes DIY., 2013).

Masalah pertumbuhan dan perkembangan masih menjadi permasalahan kesehatan pada anak pada saat ini. Menurut World Health Organization (WHO) tahun 2013, mencatat bahwa setiap tahun lebih dari 200 juta anak mengalami gangguan pertumbuhan dan perkembangan. Data dari UNICEF (2011), didapatkan bahwa angka kejadian gangguan pertumbuhan dan perkembangan pada anak usia balita khususnya gangguan perkembangan motorik didapatkan $(27,5 \%)$ atau 3 juta anak mengalami gangguan.

Kurangnya perhatian pada pengasuhan anak akan menimbulkan dampak bagi pertumbuhan dan perkembangannya. Dampak dari pertumbuhan dan perkembangan akan menimbulkan gangguan pada perkembangan kognitif, motorik, sosial dan emosional yang akan menyebabkan anak cenderung akan mengalami masalah di sekolah (McGreegor et al., 2007 dalam Rusmilawaty \& Hapisah, 2015). 
E Oktavianto, Karimah, E Timiyatun, A Badi'ah Memperbaiki Kelekatan antara Pengasuh dan Anak
Praktik pengasuhan orangtua memainkan peranan penting dalam terjadinya masalah kelekatan. Smeekens menjelaskan bahwa dampak negatif dari hubungan yang buruk akan berpengaruh pada fungsi perkembangan anak, artinya bahwa kelekatan tidak hanya berpengaruh pada tingkat perilaku dan emosional anak, tapi juga pada fungsi fisiologis dan emosi anak (Smeekens et al., 2010 dalam Hanisah\& Dasuki, 2012). Menurt World Health Organization (2004), sekitar 55\% anak diklasifikasikan dalam security attachment dan sekitar $43 \%$ anak diklasifikasikan dalam insecurity attachment dibagi menajadi 3 pola kelekatan yaitu: sekitar $20 \%$ anak termasuk dalam kelompok Insecure-avoidant, sekitar $15 \%$ anak termasuk dalam kelompok Insecure-ambivalent dan sekitar $8 \%$ anak masuk dalam kelompok Insecure-disorganized.

Berdasarkan hasil studi pendahuluan di TK LKMD Singosaren, Banguntapan, Bantul Yogyakarta, dengan melakukan wawancara pada 7 orang ibu, 5 di antaranya memiliki kualitas kelekatan yang tidak aman yang berdampak kepada perilaku anak seperti anak sering marah karena kepergian ibu, anak terus menangis, anak sering menuntut dan tidak sabaran dengan ibunya, anak sering rewel dan bersikeras sampai apa yang dia inginkan dapat terlaksana.

Melihat keadaan anak yang memprihatinkan tersebut, maka perlu strategi untuk mengatasinya, khususnya dalam masalah pengasuhan. Salah satunya adalah dengan mengadakan pelatihan bermain pada ibu untuk meningkatkan kelekatan antara ibu dan anak.

\section{METODE}

Penelitian ini merupakan jenis penelitian pra-eksperimantal, dengan desain penelitian one-grup pre-test \& post-test without control. Populasi dalam penelitian adalah semua ibu dari anak usia prasekolah di TK LKMD Singosaren Banguntapan, Bantul, Yogyakarta, yang berjumlah 31 ibu. Pengambilan sampel menggunakan teknik purposive sampling dan didapatkan hasil 18 pasang ibu dan anak.

Instrumen yang digunakan dalam penelitian ini adalah modul pelatihan bermain, SAP, alat dan bahan pembuatan playdough, LCD dan kuesioner. Alat penilaian kelekatan antara anak dan ibu menggunakan kuesioner Attachment Q-set (AQS). Terdiri dari 37 item pertanyaan, dari ke 37 pernyataan tersebut terdiri dari secure base attachment behavior 19 pertanyaan (pertanyaan no 1-19) dan insecure base attachment behavior sebanyak 18 pertanyaan (pertanyaan no 20-37).

Penilaian kelekatan dilakukan beberapa kali yakni sebelum dilakukan intervensi bermain (pretest), seminggu setelah dilakukan intervensi bermain (postest 1) dan 3 minggu setelahnya (postest 2).

Intervensi pelatihan bermain dilakukan dengan ceramah tanya jawab, simulasi pembuatan mainan dari playdough serta menggunakanya untuk storytelling. Setelah dilakukan pelatihan, ibu disupervisi untuk melakukanya kepada anak saat berada di rumah.

Analisis data dalam penelitian ini menggunakan analisis univariat dan analisis bivariat. Analisis bivariat dilakukan dengan uji Wilcoxon. Uji normalitas menggunakan uji Shapiro-Wilk karena jumlah sampel penelitian 
E Oktavianto, Karimah, E Timiyatun, A Badi'ah Memperbaiki Kelekatan antara Pengasuh dan Anak

$\leq 50$. Hasil uji normalitas data menggunakan uji Shapiro-Wilk didapatkan nilai $p<0.05$, sehingga datanya tidak terdistribusi normal

\section{HASIL}

Terjadi peningkatan skor kelekatan anak dari sebelum dilakukan pelatihan bermain pada ibu dan setelah diberikan pelatihan bermain. Peningkatanya adalah dari rata-rata skor pre-test 111.83 menjadi 137.44 pada post-test 1 (nilai selisihnya $=25.61$ ), dan meningkat lagi menjadi 140.05 pada post-test 2 (nilai selisihnya $=28.22$ ). Hasil uji Wilcoxon, didapatkan nilai $p=0.000$ baik saat postest 1 maupun saat postest 2. . Karena nilai $p<0.05$, berarti ada pengaruh pengaruh pemberian pelatihan bermain pada ibu terhadap kelekatan anak prasekolah. (Gambar 1).

Mayoritas ibu berusia 31-40 tahun yakni berjumlah 13 responden (72.2\%), berpendidikan SMA yakni berjumlah 9 responden $(50.0 \%)$, berpenghasilan > UMR yakni berjumlah 10 responden (55.6\%), semua ibu belum pernah mendapat informasi tentang pelatihan bermain berjumlah 18 responden (100\%). (Tabel 1).

Tabel 1. Karakteristik Responden $(n=19)$

\begin{tabular}{lcc}
\hline Karakteristik & Frekuensi & Persentase \\
\hline Usia ibu & 2 & \\
$20-30$ thn & 13 & $11.1 \%$ \\
$31-40$ thn & 3 & $72.2 \%$ \\
$41-50$ thn & 5 & $16.7 \%$ \\
Pendidikan ibu & 9 & $27.8 \%$ \\
SMP & 4 & $50.0 \%$ \\
SMA & & $22.2 \%$ \\
PT & 10 & $55.6 \%$ \\
Penghasilan keluarga & 8 & $44.4 \%$ \\
$\quad$ UMR & & \\
< UMR & 18 & $100 \%$ \\
Mendapat pelatihan bermain sebelumnya & 0 & $0 \%$ \\
$\quad$ Pernah & & \\
Tidak & &
\end{tabular}

\section{Kelekatan Anak}

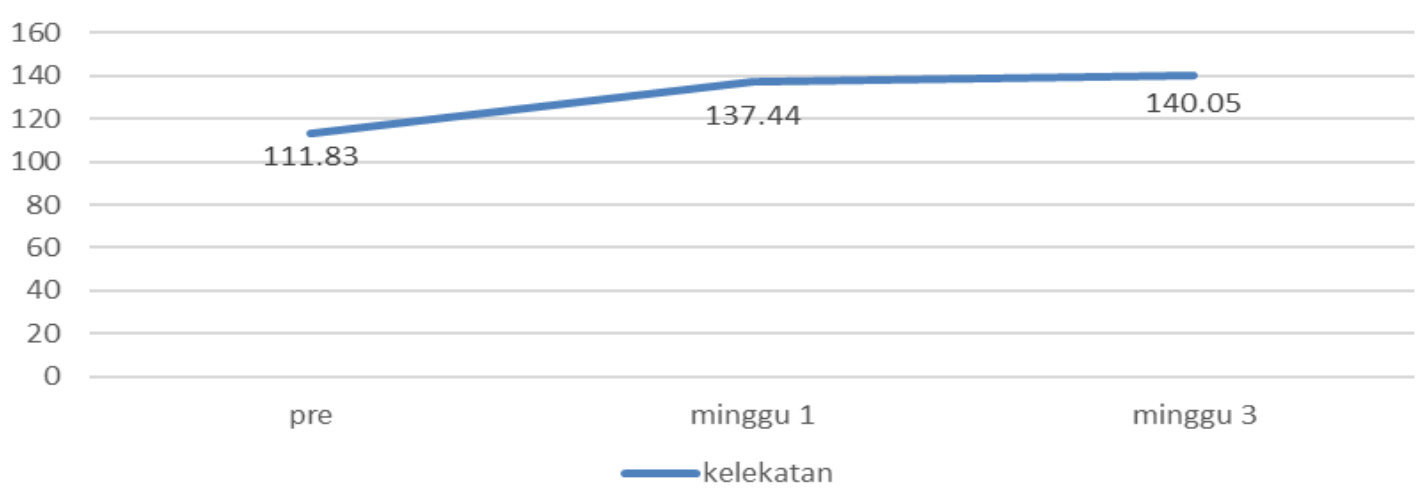

Uji Wilcoxon: Mean rank $=9.50$ p-value $=0.000$

Gambar 1. Peningkatan skor rata-rata kelekatan anak antara sebelum dan setelah pelatihan bermaian pada ibu 
E Oktavianto, Karimah, E Timiyatun, A Badi'ah Memperbaiki Kelekatan antara Pengasuh dan Anak

\section{PEMBAHASAN}

Anak merupakan dambaan keluarga. Setiap keluarga mengharapkan anak yang mampu tumbuh dan berkembang secara optimal, baik secara fisik, mental, kognitif maupun sosial. Periode penting dalam tumbuh kembang anak adalah pada usia di bawah lima tahun (Soetjiningsih, 2012). Para ahli mengatakan bahwa anak usia dini disebut sebagai masa emas (golden age period), usia prasekolah merupakan masa kritis dalam perkembangan siklus hidup seseorang. Sudaryanti (2012), menyatakan bahwa anak usia dini memiliki perkembangan fisik, motorik, intelektual, dan sosial yang sangat pesat dan menjadi landasan awal bagi tumbuh dan kembang anak

Seorang anak dalam proses tumbuh kembangnya, dipengaruhi pertama kali secara langsung oleh lingkungan keluarganya yakni pengasuh utamanya. Peran ibu sebagai pengasuh utama sangatlah dominan untuk mengasuh dan mendidik anak agar dapat tumbuh dan berkembang dengan baik. Wijirahayu et al. (2016), dalam mengasuh dan mendidik anak, salah satu faktor yang berperan penting adalah kualitas kelekatan antara pengasuh-anak. Kelekatan secara umum dikategorikan menjadi dua, yaitu kelekatan aman (security attachment) dan kelektan tidak aman (insecurity attachment).

Mayoritas anak pada penelitian ini memiliki kelekatan yang tidak aman, hal ini disebabkan karena kurangnya kedekatan antara ibu dan anak, mereka hanya mendampingi anak saja tanpa adanya suatu kedekatan emosional seperti memberikan perhatian, kasih sayang, rasa nyaman, dan lain-lain.
Kelekatan adalah ikatan emosional yang dibentuk seorang individu dengan orang lain yang bersifat spesifik dan mengikat dalam suatu keadaan yang bersifat kekal sepanjang waktu (Ainsworth, 1989 dalam Wijirahayu et al., 2016). Kelekatan bukanlah ikatan yang secara alamiah, ada serangkaian proses yang harus dilalui untuk membentuk suatu hubungan kelekatan dan hal tersebut memerlukan waktu, dan terbentuk sejalan dengan kemampuan kognitif anak (Kaplan dalam Bayani \& Sarwasih, 2013). Hubungan yang dibina antara ibu dengan anak akan bertahan cukup lama dan memberikan rasa aman walaupun figur lekat tidak tampak dari pandangan anak. Anak yang merasa yakin pada penerimaan lingkungan akan mengembangkan kelekatan yang aman (security attachment) dengan figurlekatnya dan mengembangkan rasa percaya diri tidak hanya pada ibu tetapi juga terhadap lingkungannya, hal ini akan berpengaruh positif terhadap proses perkembangannya (Holden, 2010 dalam Wijirahayu et al., 2016).

Anak dengan kelekatan yang tidak aman (insecurity attachment) tidak memiliki kemampuan untuk mengatur emosi. Wijirahayu et al. (2016), menyatakan bahwa anak dengan kelekatan yang tidak aman akan sulit mengatur emosinya sehingga apabila ada larangan atau keinginan yang tidak terpenuhi, anak akan merengek, menangis meraung-raung, berguling-guling, atau bahkan mengamuk (temper tantrum). Sebaliknya, anak dengan secure attachment akan memiliki kemampuan untuk mengatur emosi. Hal ini akan membawa pengaruh postif terhadap perkembangan sosial-emosi anak. Oleh karena itu, kelekatan ibu tidak 
E Oktavianto, Karimah, E Timiyatun, A Badi'ah Memperbaiki Kelekatan antara Pengasuh dan Anak

hanya menularkan kehangatan secara fisik namun juga kognitif dan afektif yang dirasakan bersama.

Hasil penelitian menunjukkan bahwa pelatihan bermain dapat membantu responden dalam merubah hubungan kelekatan anak. Rata-rata skor kelekatan mengalami peningkatan yang nyata, dari awal sebelum pemberian pelatihan bermain yaitu 111.83, meningkat menjadi 137.44 saat 1 minggu sesudah pelatihan bermain (nilai selisihnya $=25.61$ ), kemudian meningkat menjadi 140.05 saat 3 minggu sesudah pelatihan bermain (nilai selisihnya $=140.05$ ) . (Gambar 1).

Pelatihan bermain pada ibu melatih ibu sebagai pengasuh untuk menciptakan permainan dengan anak, karena dengan bermain akan meningkatkan kualitas hubungan kelekatan antara ibu dan anak. Ibu yang sering bermain dengan anak, akan cenderung lebih sering dekat dengan anak, memberikan perhatian, kasih sayang dan rasa nyaman sehingga dapat menimbulkan hubungan kelekatan yang aman (security attachment).

Beberapa penelitian tentang pelatihan bermain pada ibu sebagai pengasuh mendukung hasil dari penelitian ini. Oktavianto dan Mubasyiroh (2017), menyimpulkan hasil penelitianya bahwa pelatihan bermain pada pengasuh dapat meningkatkan pengetahuan, sikap dan ketrampilan pengasuh dalam bermain dengan anak. Perbaikan pengetahuan, sikap dan ketrampilan ini sebagai dasar untuk melakukan pengasuhan yang lebih baik. Penelitian dilanjutkan oleh Oktavianto dan Paramita (2017), yang mendapatkan hasil bahwa pelatihan bermain pada pengasuh dapat meningkatkan sensitivitas pengasuhan. Oktavianto et al. (2018), menguji efektifitas bermain terhadap kualitas interaksi dan didapatkan hasil bahwa pelatihan bermain pada pengasuh dapat meningkatkan kualitas interaksi pengasuh dan anak prasekolah.

Dari hasil beberapa penelitian tentang pelatihan bermain tersebut dapat ditarik kerangka pemikiran bahwa pengasuh yang memiliki pengetahuan yang baik tentang pelatihan bermain akan menunjukkan sikap yang baik pula terhadap pengasuhan anak serta dapat meningkatkan keterampilan pengasuh. Kemampuan ini akan membuat pengasuh lebih percaya diri dalam mengasuh anak. Kepercayaan diri ini akan menimbulkan sensitivitas pengasuhan dan akan terjalin komunikasi atau kualitas interaksi yang baik antara pengasuh dengan anak. Pada akhirnya menimbulkan hubungan keleketan seperti: rasa nyaman, perhatian, rasa kasih sayang antara pengasuh dengan anak.

Pelatihan menurut Strauss dan Syless merupakan suatu tindakan untuk mengubah pola perilaku, bagian dari proses pendidikan dalam rangka memperoleh dan meningkatkan ketrampilan, dalam waktu yang singkat dan metode yang dipakai lebih mengutamakan praktek dari pada pemberian teori (Notoatmodjo, 2014). Tujuan dari pelatihan pada ibu ini adalah meningkatkan kemampuan para ibu dalam bermain dengan anak guna mendukung praktek pengasuhan.

Pelatihan pada ibu mengandung upaya untuk meningkatkan praktik pengasuhan anak agar pengetahuan, sikap dan keterampilanya meningkat. Sehingga pengasuh dapat bermain dengan anak dengan baik, 
E Oktavianto, Karimah, E Timiyatun, A Badi'ah Memperbaiki Kelekatan antara Pengasuh dan Anak meningkatnya parenting self efficacy yang akan menimbulkan sensitivitas pengasuhan, dari rasa sensitivitas tersebut akan terjalin kualitas interaksi yang baik sehingga timbul kelekatan yang aman (security attachment) antara pengasuh dengan anak.

Pada penelitian ini, pelatihan bermain pada ibu menggunakan permainan playdough dan storytelling untuk bermain dengan anak. Menurut Difatiguna et al. (2015), playdough merupakan salah satu permainan edukatif yang aman untuk anak dan dapat mengembangkan seluruh aspek perkembangan anak usia dini terutama dalam melatih motorik halus pada anak usia dini. Sedangkan menurut Muallifah (2013), dengan storytelling mampu meningkatkan kelekatan antara orangtua dan anak karena dalam storytelling orangtua mampu membangun komunikasi efektif, memberikan suasana menyenangkan dan membuat anak merasa nyaman dengan berbagai cerita yang diberikan.

\section{KESIMPULAN DAN SARAN}

Dari hasil penelitian dan pembahasan yang telah dipaparkan, maka dapat ditarik kesimpulan bahwa pelatihan bermain pada ibu dapat meningkatkan kelekatan anak. lbu diharapkan konsisten dalam melakukan aktivitas bermain dengan anak dan kreatif untuk menciptakan permainan-permainan baru sehingga kelekatan anak kepada ibu akan semakin meningkat. Peneliti selanjutnya dapat melakukan penelitian yang sama tapi dengan responden yang berbeda usia, misalnya pengasuh bayi atau toddler serta menggunakan kelompok kontrol sebagai pembanding.

\section{DAFTAR PUSTAKA}

Bayani, I., Sarwasih, S. (2013). Attachment dan peer group dengan kemampuan coping stress pada siswa kelas VII di SMP RSBI Al Azhar 8 Kemang Pratama. SOUL: Jurnal IImiah Psikologi, 6, 77-96.

Difatiguna, S., Surahman, M., Rini, R. (2015).Pengaruh aktivitas bermain menggunakan playdough terhadap kemampuan motorik halus pada anak. Jurnal Pendidikan Anak, 1, 1-11.

Dinkes DIY. (2013).Profil kesehatan Daerah Istimewa Yogyakarta tahun 2013. Diakses tanggal 10 Januari 2017 dari https://www.dinkesjogjaprov.go.id.

Hanisah, B., Dasuki, D. (2012). Hubungan antara pengasuh pengganti dan sensitivitas pengasuhan terhadap kualitas kelekatan anak buruh migran di Kabupaten Lombok Timur Provinsi Nusa Tenggara Barat (doctoral dissertation).tersedia dari Electronic Theses and Dissertation. (UGM No.0170-H-2012).

Kemendikbud. (2013). Kementerian pendidikan dan kebudayaan. Diakses tanggal 10 Januari 2017 dari http://kemdikbud.go.id/kemdikbud/node/ 2322

Muallifah. (2013). Story telling Sebagai metode parenting untuk pengembangan kecerdasan anak usia dini. Jurnal Psikologi Islam (JPI), 10, 98-106.

Notoatmodjo, S. (2014). Promosi Kesehatan: Teori dan Aplikasinya. Jakarta: PT. Rineka Cipta.

Oktavianto, E., Mubasyiroh, A.A. (2017). Pelatihan bemain pada pengasuh dapat meningkatkan pengetahuan, sikap, ketrampilan pengasuh. Health Science and Pharmacy Journal, 1,20-29.DOI: https://doi.org/10.32504/hs pj.v1i1.7

Oktavianto, E., Paramitha, K.A. (2017). Pelatihan bermain pada pengasuh dapat meningkatkan sensitivitas pengasuhan anak prasekolah. Prosiding Seminar Nasional Teknologi Informasi (SNATIK): Teknologi Informasi Menuju Smart Health Care (2017):hal215-238

Oktavianto, E., Hartiningsih, SN.,Timiyatun, E., Lesmana, TWI., Badi'ah, A. (2018). Pelatihan bermain pada pengasuh meningkatkan kualitas interaksi antara pengasuh dan anak prasekolah. Riset Informasi Kesehatan, 7, 90-98.DOI: https://doi.org/10.30644/rik.v 
$7 \mathrm{i} 1.138$

Rusmilawaty \& Hapisah. (2015). Pengaruh pengasuhan ibu terhadap perkembangan anak prasekolah di Kecamatan Banjarmasin Barat Kota Banjarmasin Tahun 2012. Journal Caring, 2, 1-12.

Soetjiningsih \& Gde Ranuh, I.G.N. (2012). Tumbuh Kembang Anak (edisi ke-2). Jakarta: EGC.

Sudaryanti, S. (2012). Pentingnya pendidikan karakter bagi anak usia dini. Jurnal Pendidikan Anak, 1, 11-20.

UNICEF. (2011). Care for development in three central asian countries: report of a process evaluation in Tajikistan, Krgyys Republic, and Kazakhtan. Diakses tanggal 10 Januari 2017 dari http://www.unicef.org

Wijirahayu, A., Krisnatuti, D,, Muflikhati, I. (2017). Kelekatan ibu-anak, pertumbuhan anak, dan perkembangan sosial emosi anak usia prasekolah. Jurnal IImu Keluarga \& Konsumen, 17, 171-82.

World Health Organization (WHO).(2013). Nurturing human capital along the life course; investing in early child development. Geneva: WHO Meeting Report. Diakses tanggal 10 Januari 2017 dari http://www.who.int

World Health Organization (WHO) (2004). The importance of caregiver-child interactions for the Survival and Healthy development of young children: a review. Geneva: World Health Organization. Diakses tanggal 10 Januari 2017 dari http://whqlibdoc.who.int 